\title{
Moo in Your Face: Researching, Designing, and Programming a User-Friendly Interface
}

\author{
MARK HAAS \\ Dakota State University \\ Clinton Gardner \\ Salt Lake Community College
}

\begin{abstract}
Promoters of multi-user, object-oriented domains (MOOs) in composition point to the capability for student collaboration and conversation throughout the writing process as a valuable feature; detractors, however, draw attention to the difficulty for students to negotiate the somewhat arcane, text-based $M O O$ interface, which affords no easy, intuitive way for students to learn how to exist in that virtual world, and often results in confusing conversations. The learning curve of a $\mathrm{MOO}$ and its confusing interface blockade effective use. Current research on Web-browser interface design provides several principles for developing a user-friendly TELNET interface that creates a sense of presence for the user. An IBM/PC-compatible interface, PUEBLO from Chaco Communications, Inc., allows developers to modify the interface to provide a sense of presence for the user. In addition, access to the sites for non-IBM users was developed. For Web browsers, a Java-based interface and a WOO interface allow students to access and function in the $\mathrm{MOO}$ more quickly than a purely text-based client did. Work in programming a variety of interfaces has led to a more intuitive environment for students and instructors who use MOOs.
\end{abstract}

computer-mediated communication interface design Java MOO PUEBLO sense of presence TELNET WOO

\section{INTRODUCTION}

Since computers were first used in composition classrooms, there have been consistent difficulties in training student users to use the technology while accomplishing the goals of the class. This training difficulty is most clearly manifested in computer-mediated communication (CMC) environments like multi-user, object-oriented domains (MOOs). Promoters of such environments point to collaboration and empowerment as a MOO's most valuable features. Detractors draw attention to the difficulty for students to learn the 
intricacies of computer-based environments without a great deal of training. Detractors also suggest that many users find the somewhat arcane, text-based interface extremely difficult to negotiate. For example, the standard method of working on a MOO (via a no-frills TELNET client) affords no easy way for students to learn how to participate in this virtual world. To become comfortable with a MOO, students have to use it for several days and become knowledgeable of a series of commands, all while building a conceptual idea of the virtual space. The learning curve of the MOO, and its confusing interface, detractors insist, blockades effective use.

In this article, we will explore the effects interfaces can have on users of MOOs. To establish a context for MOOs in CMC, we will first review relevant research on the value of CMC to composition studies, linking that research with an overview of two important CMC systems: Daedalus InTEgrated Writing Environment, and an environment that carries such a system even farther-a MOO. After an overview of the successes we have attained in using MOOs, we focus on the problems that using a MOO as a communications environment presents. Determining that the textual interface of the MOO is the source of the difficulties, we demonstrate the development of a graphical interface that uses the familiar principles of Web browsers. It allows students to share in a MOO more readily than with the nongraphical interface. Throughout the article, we will clearly demonstrate the effects of the research we have conducted and the programming we completed to address our audience's needs and desires. In all, our purpose for designing the interface is to ensure that MOOs continue to be used and be at the forefront of CMC environments.

\section{COMPOSITION THEORY AND THE VALUE OF CMC}

Because of the simultaneous influences of social constructivism and computer-mediated communication's potential for collaborative work, much of the scholarly discussion of CMC's value for writing instruction has occurred in the past decade. To illustrate, several articles in the 1990 collection Computers and Community highlight typical arguments. Thomas T. Barker and Fred Kemp (1990) concluded that an understanding of the educational environment from the context of network theory empowers students and transforms the classroom into a social community of learning. What Barker and Kemp saw as CMC's impact on students and teachers echoes throughout the majority of the essays. Kathleen Skubikowski and John Elder (1990), in their contribution "Computers and the Social Contexts of Writing," discussed the student construction of a writing community through networked corresponding. Several other scholars focus on political and pedagogical issues, such as feminism, teacher decentering, student collaboration, and student authority (Handa, 1990; Langston \& Batson, 1990; Selfe, 1990). Carolyn Handa (1990), editor of the collection and writer of the final essay, provided a key to the social constructivist use of the computer in composition. Acknowledging that computers are changing the dynamics of the classroom and larger educational contexts, Handa called for the use of computer-mediated communication (CMC) over computer-aided instruction (CAI):

The pedagogical effect of $[\mathrm{CMC}]$ is that we remove ourselves from the position of authority in order to challenge the traditional classroom dynamic .... Computers can in this [CMC] context demarginalize students traditionally excluded at the boundaries of discourse, validate the contributions of students ... and allow more creative invention to occur. (p. 170) 
Handa thus theoretically grounds further integration of CMC in the composition community. The publication of further collections that focus on issues involved with computer use (see, for example, Hawisher \& Selfe, 1991; Selfe \& Hilligoss, 1994) seem to indicate that investigating and using computer-mediated communication (CMC) is appropriate for students of composition and rhetoric.

\section{CMC IN DAedalus AND A MOO}

Many writing instructors cut their CMC teeth on DAEDALUS, which provides local-area network (LAN) support representative of Barker and Kemp's (1990) networked environment. In one module of the environment, INTERCHANGE, students log into the DAEDALUS server and communicate synchronously with each other by typing in and sending their messages. Daedalus Group, Inc. (1997), producers of the package, explain INTERCHANGE as follows:

INTERCHANGE facilitates synchronous, or "real-time," discussions for whole classes, small groups, or both simultaneously. Students compose private messages and send them to all the members of a discussion group for immediate viewing. Transcripts of these discussions are automatically saved to your file server, and can be saved to disk or printed and reviewed at any time. (online)

The result is a scrolling screen of messages identified by each student/sender's name. This textual conversation is typically used for a variety of purposes, including helping writers gather ideas and start their papers, sharing student texts and encouraging peer feedback, and bringing all students into class discussions.

Although DAEDALUS provided a great introduction to networked environments, it soon became limiting. DAEDALUS was often slow when many users were connected, required a great deal of manipulation from keyboard to mouse to interact, and wasn't adaptable for specific uses (it was not programmable). Moreover, although DAEDALus was originally intended to be an integrated writing environment, most teachers used it only for the INTERCHANGE (chat) element, making it extremely expensive for a "chat" program.

Another, often neglected domain of CMC became popular: the multi-user domain (MUD). A MUD is a network-accessible, multiparticipant, virtual reality that is primarily text-based (Bruckman, 1992; Curtis, 1993). Originally produced in 1978 as multi-user adventure games based upon the popular role-playing game Dungeons and Dragons, MUD environments have proliferated and diversified. Unlike DAEDALUs, which was originally limited to local area networks, MUDs allowed access from any TELNET program, anywhere around the world. Also, one variety of MUDs, termed MOO, have developed as object-oriented spaces, allowing interaction in and with the environment beyond conversation: Students could move between virtual spaces, interact with other objects, and enhance the environment through constructing and programming objects.

\section{INTEGRATION OF MOO INTO ENGLISH COURSES-A SUCCESS STORY}

The Salt Lake Community College (SLCC) English Department began using a MOO server in 1994 as a means of supporting distance-education composition classes, and to offer an alternative means of communication for in-person composition courses, peer- 
response tutoring, instructional development, and writer-to-writer collaboration. SLCC's Virtual Writing Center MOO (VWCMOO) (bessie.englab.slcc.edu port 7777) was developed in part through a State of Utah Higher Education Technology Initiative (HETI) grant obtained to create online composition courses such as SLCC's Online English 1010 (see http://www.slcc.edu/wc/online.htm) (Bown, 1996).

\section{Success at SLCC}

Along with Louise Bown and Stephen Ruffus (1998), the coordinators of the Online English 1010 grant, many other instructors were interested in the possibilities of using the MOO as an alternative to traditional classroom activities. SLCC instructor Elisa Stone (1996), for example, saw the MOO as a possible way to lessen the gender bias of the traditional classroom where she saw that male students tended to dominate conversations and group activities, and women students were often stifled. Like Handa (1990), Louise Bown (1996), who was using the MOO in both her traditional classes and in the online composition course, saw the MOO as a means of decentering the traditional classroom. On the MOO, she believed, the power structure of the in-person classroom was dissipated. Instead of just being in charge, the instructor became more of a participant in the class. Stone, who taught the Online English 1010 course after the initial developmental stages, came to similar conclusions:

\footnotetext{
For one thing, the traditional classroom is set up to privilege the teacher's authority as a central figure by granting a special desk and chair, front and center, a board, podium, etc., to this privileged leader. In the Moo classroom I'm just a name, visually, like anyone else. Of course my comments on the Moo were given more weight than they would have been if I weren't the teacher, but clearly the power distribution was more subject to challenge in the online atmosphere. (Bown \& Ruffus, 1998, online)
}

Like other scholars who study CMC, Stone concluded that students take on more responsibility and develop more successful strategies of negotiating discussion and collaborative idea building and writing.

\section{Success at DSU}

As at SLCC, The Virtual Trojan Center MOO (VTCMOO) (alpha.dsu.edu port 7777) grew out of a desire to provide online education at Dakota State University. Started in the Spring of 1997, the VTCMOO was originally conceived as a virtual space station (Deep Space University MOO, still running at alpha.dsu.edu port 4444), but was redesigned as a counterpart to the bricks and mortar of the Madison, South Dakota campus. VTCMOO initially gave distance-education students a means to interact with other students in nonacademic situations similar to hallway chat and dorm interactions. However, through a grant from DSU's Office of Distance Education, the MOO administrator developed instructional methods and materials and now uses the MOO in composition and technical writing courses, both online and in the classroom.

One interesting development that occurred during the grant project was the increased involvement of students beyond mere MOO chat. Because of DSU's unique mission to integrate computer technology into every discipline (DSU's English degree is in English for Information Systems, for example), students are often intrigued by and excited about 
digging into various technologies. One student, Joe Kepley, had some background in the adventure-gaming side of MUDs, so naturally became involved in the project. He worked to produce three-dimensional images that were actually virtual reality markup language (VRML)-ready. Working within the space-station environment, he envisioned large-scale projects for different departments, including the design of Cartesian space and space craft that operated in that space; the possibility of moving beyond Cartesian space to relative Einsteinian space; the construction of planets with ecosystems and social systems for conceptual study in the physical and social sciences; and the development of economic simulations for business applications. Another student, Stacey Peters-Walters, became involved in the VTCMOO. To help students and teachers communicate, act, and enhance the MOO, she assisted writing a MOO manual (Haas \& Peters-Walters, 1997), which included information for accessing the MOO, getting a TELNET client, and building and editing objects for teaching purposes. Both Joe and Stacey illustrate the potential for student involvement in MOO and interface development.

\section{Success Outside SLCC and DSU}

Interest in VWCMOO was not limited to SLCC and DSU students and faculty, however. Students, scholars, and other people from around the world interested in writing, distance education, or educational uses of MOOs began working on VWCMOO and VTCMOO. Through these efforts, the MOO users shaped them to be places "on the Internet where people get together to take online writing courses, to talk about writing, or just to create spaces for and about writing" (Gardner, 1998). (In fact, the writers of this article initially met each other on VWCMOO because we were both interested in discussing computermediated communications, and in developing the MOO for educational purposes.)

\section{PROBLEMS WITH MOO}

Aside from these successes, however, everyone involved in the developing MOOs immediately saw problems with MOOs as a communications environment. We saw difficulties in

- the multithread concept of the MOO conversation itself, which makes it difficult for new users to read and participate in a MOO conversation, and

- the nonintuitive nature of a text-only world, which inhibits students from easily manipulating and understanding their presence in the virtual world.

\section{Difficulty of Multiple Threads}

The most common initial concern was the "party atmosphere" of the MOO: Real-time online class discussions through a MOO is like being in a room of 20 people and hearing absolutely everything that everyone says. Threads of conversations flow across the screen in quick succession, often bewildering the novice MOO user. Bown and Ruffus (1998) later concluded in their report on the HETI grant that conversation on the MOO 


\begin{abstract}
the screen, although students can scroll up and read comments they may have missed. If the comments move quickly, students can become frustrated. This is one of the reasons why we put them in small groups. The MOO creates a new discourse unlike any other, a hybrid of speaking and writing. Therefore, discussions are not always as well developed as are typically achieved in a face-to-face interaction. (online)
\end{abstract}

The multithreaded nature of the MOO conversation, however, is a difficulty that is not easy to solve through programming. For instance, if one limits the number of participants who can communicate with one another by programming, then the nature of a MOO as a communications environment changes. The complexity of MOO conversations is a part of the medium, and can be valued because it provides a place where many users can share in a common conversation, unlimited by physically based constraints of turn-taking, or interrupting one another by "talking over the top" of someone else. A MOO conversation seems to give equal importance to all utterances, and a reader is pushed to become a more adept reader to follow the threads of conversations. Because computer-mediated conversations are inherently different from in-person or epistolary modes of communication and often consist of complicated threads of conversation, we determined that it was very important that students be comfortable with the environment in which such complex conversations would take place. Otherwise, students would continue to be confused by the conversation as well as overwhelmed by the complexity of the MOO.

\title{
Orientation-Getting Lost
}

One of the benefits of the MOO also became a problem: The virtual space became confusing for students, often resulting in their becoming lost in the MOO. To illustrate, the Dakota State University MOO was first built to resemble a space station with the name Deep Space University (DSUMOO). However, people often became confused about where they were in the MOO, not understanding port and starboard, or how to move between rooms. For example, students would often wander off or get stuck in a room when first entering the MOO and the teacher would have to spend time instructing them on how to rejoin the class. As a result, class time was spent off-task, and students often missed out on the discussion.

To navigate the virtual world, students and instructors had to be comfortable with the virtual space of the place, as well as with several nonintuitive MOO commands. For instance, exits are listed in the description of the room, and students often overlooked their names. Also, understanding commands like look note on board was somewhat daunting.

Likewise, the first time that SLCC offered Online English 1010, the instructors spent two weeks training the students and getting them familiar with the virtual MOO environment. At that time, students found it difficult to remember commands to navigate VWCMOO, and were not easily able to visualize their position in the virtual world. Many students became frustrated because they had to learn so much about the technology and an imaginary world at the expense of the content of the course.

\section{TEXTUAL INTERFACES-THE SOURCE OF THE PROBLEMS}

In listening to students and instructors, we noticed a common element in discussions of problems: In part, learning to operate in the MOO was very difficult because it was a 


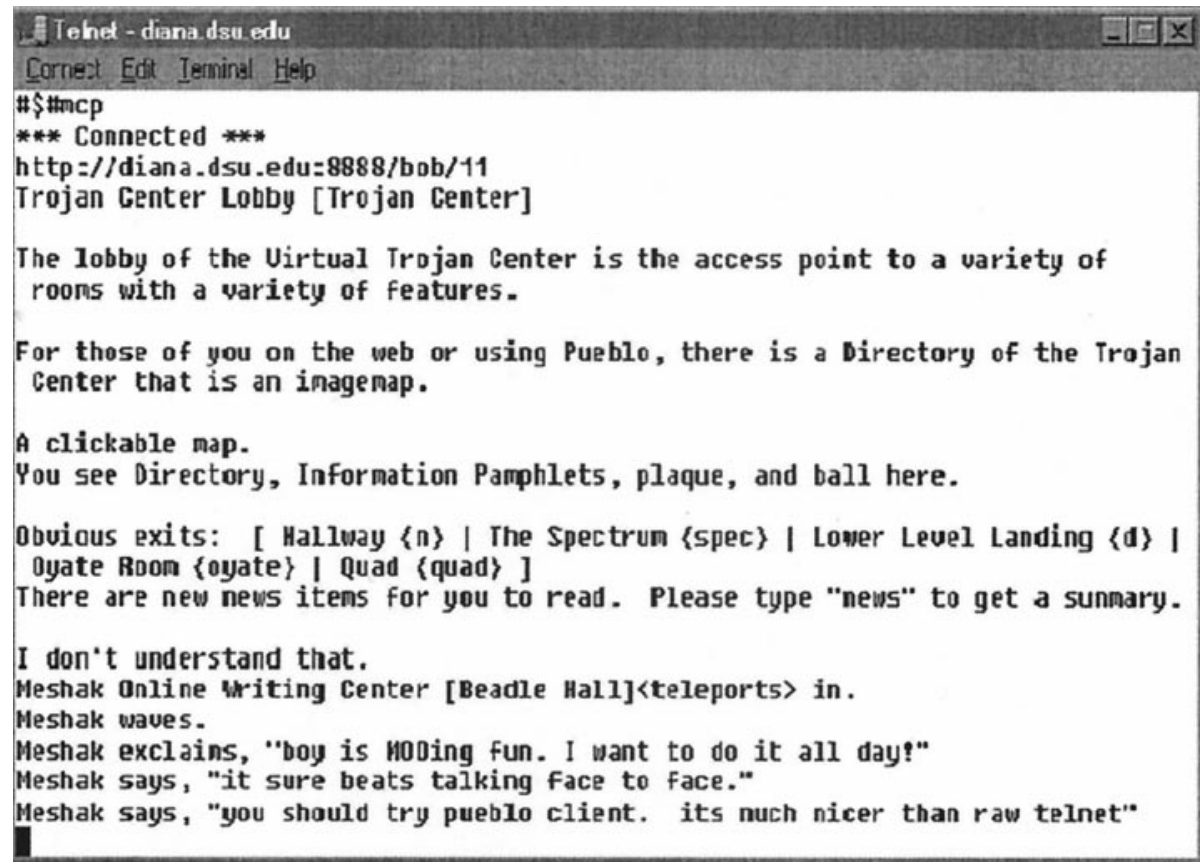

Figure 1. A bare TELNET client accessing the Virtual Trojan Center MOO (VTCMOO) diana.dsu.edu port $7777 .^{1}$

text-only environment and required a bare TELNET client - a computer application that did little to make the MOO easier to use. TELNET clients are programs that run on the user's computer and allow her to connect to a server using the Internet protocol called "Telnet." Unlike a Web browser, for instance, all "bare" TELNET clients are text-only (see Figure 1). Their obvious benefit, nevertheless, is that they allow the student to interact in real time.

Overall, so-called bare TELNET clients require a great deal more experience to operate than a simple Web browser. In the history of computer interface, command-line systems like bare TELNET have moved very quickly to menu-based systems and then to more intuitive graphical user interfaces. As Ziegler, Vossen, and Hoppe (1990) surmised, "since the early 1980s a new generation of office workstations has become available . . which are trying to solve... usability problems by introducing a highly visualized, objectoriented interaction style between user and system" (p. 27). Such systems, termed direct manipulation by B. Schneiderman (1982), allow the user to more efficiently complete tasks because, "the more the functionality of a system is broadened, the more the ease of learning is determined by the degree of consistency of use between the different functional domains" (Ziegler et al., 1990, pp. 27-28).

An analogy between text-only TELNET interfaces and DOS-like command line inter-

\footnotetext{
${ }^{1}$ All text, including descriptions, exit signifiers, and conversation sent from the MOO server scrolls up the screen and eventually disappears. Users must type in all movement and manipulation commands. Note the "Obvious exits" list, which requires the user to type in the exit name that is in the braces.
} 
faces helps to explain the difficulties novice users face. It is interesting, however, that defenders of the command-line interface have dropped by the wayside, yet defenders of text-only MOOs seem to hold on. Like command-line interfaces, a text-only MOO requires the user to learn many commands and unfamiliar MOO concepts before she can function, or to put it more appropriately, before she can communicate and exist in the virtual world. Not only must the user grasp basic commands such as speaking (with either "say" or a quotation mark preceding their statement), looking at the space they are in (with the command "look"), or manipulating objects in that space (through a variety of commands), but they must also read the text interface thoroughly to derive visual space cues, and intuit from the interface how to get to other rooms. To get to a new discussion space, the user must type in the specific "exit name" listed on the MOO. When users type this in, they are moved to the new space. On MOOs, these exit names are usually listed in an "Obvious Exits" list users see when first entering a room.

For example, if the user were standing in a room called a "cafe," and wanted to go to the "garden," she would have to type the specific exit name that is linked to the "garden." All the while, the only physical cueing is the descriptive text provided to the reader/user (see Figure 1).

Although one might argue that making the MOO a completely text-based world forces its users to become better readers (as we believed when we first started writing for MOOs), based on our experience, the difficulties of requiring the user to learn a set of obtuse commands and to grasp even more foreign proto-physical concepts far outweigh the benefits. Many of us would like students to learn to program a MOO; however, most of the students we have encountered do not want to go that deep into the environment. Most want to get into the MOO, participate in a conversation, and, perhaps, manipulate objects someone else created. Such behavior does not limit a student's use of the MOO any more than any computer usage is limited because a user does not know how to program, but makes use of programs already existent on the system. Granted, if a user learns to program the computer, she will tap into a resource that she has not previously used, but requiring programming knowledge would be like saying all car users should learn how to rebuild their car engines so that they can get better performance.

In either case, the obtuse interface of command-line or text-only MOOs takes a great deal of time to learn and to be comfortable with, more time than many instructors can allow. Like her colleagues, Tiffany Rousculp, an instructor at SLCC, initially attempted to make use of the VWCMOO because she was very interested in the use of computers as learning tools and communication environments. At the time, VWCMOO was completely text-based. Although the maintainers had attempted to make the MOO as readable as possible, Tiffany encountered problems she later described:

Aside from broad problems with synchronous computer mediated communication (the benefits of formulating ideas in writing are not accomplished in the quick, short, and rapid discourse found in the MOOs that I've experienced,) a main concern was that the MOO (at least when I was doing it) is too cumbersome to learn, and . . . [students] become easily frustrated. (T. Rousculp, personal communication, March 3, 1998)

As one can see from Tiffany's statements, the novice MOO user is several steps removed from direct manipulation of the MOO environment and, because it is unlike anything she has experienced before-both in her real-world life and in her experience with computers, the new user encounters difficulty and frustration. The lack of direct manipulation exposes 
novices to a high order of complexity that becomes threatening, and users often are intimidated to the point of wishing never to return to the MOO, much in the way many users who encountered the command-line interface of the first personal computers fled from them and went right back to their typewriters.

\section{THE SOLUTION: GRAPHICAL INTERFACE AND A SENSE OF PRESENCE}

In other areas of the Internet, Web browsers have all but replaced the text-only interfaces of TELNET, FTP, and GOPHER clients. John Eklund (1997), focusing on cognitive mapping through interface ergonomics, argued Web browsers that provide users with a variety of navigational tools (or cues) alleviate the feeling of disorientation, or getting lost in hyperspace. In another discussion of cognitive issues relating to hypermedia, Samuel Ebersole (1997) examined cognitive issues for the users of the interface Netscape NAVIGATOR. In doing so, he posited that the key issues include "local and global coherence and cognitive overhead" (online). Cognitive overhead, as Ebersole defined it, involves the user's attempts to maintain an understanding of location in the unfamiliar interfaced environment. "In summary," he wrote, "minimizing the distractions of disorientation and unfamiliarity will enhance comprehension" (online).

To accommodate these cognitive needs in the user, theorists suggest several key aspects of Web-browser interface design: consistency, orientation, navigation, and engagement (Bardini, 1997; Ebersole, 1997; Eklund, 1995; Lombard \& Ditton, 1997). Together, these elements work to provide what theorists and researchers term a sense of presence.

According to Matthew Lombard and Theresa Ditton (1997), the concept of presence is "at the heart of it all" (online). As suggested above, a diverse group of people is interested in presence, how to create it, how to use it effectively, and how it mediates or generates a variety of responses. In reviewing relevant research, Lombard and Ditton presented a formal definition of presence: the perceptual illusion of nonmediation.

The term "perceptual" indicates that this phenomenon involves continuous (real time) responses of the human sensory, cognitive, and affective processing systems to objects and entities in a person's environment. An "illusion of nonmediation" occurs when a person fails to perceive or acknowledge the existence of a medium in his/her communication environment and responds as he/she would if the medium were not there. (online)

Presence, in their definition, can be realized in two distinct ways: (a) the interface becomes invisible or transparent, functioning as would a large open window, with the user and the content (objects and entities) sharing the same environment; and (b) the interface is transformed into something other than an interface-a social entity.

\section{Presence in the MOO}

Moving from Web-browser interface design to MOO-interface design, we find that our formulation of terms and concepts for interface design provides insight. As of yet, there has been minimal study of MOO presence beyond anecdotal information (Towell et al., 1995; Towell \& Towell, 1995, 1997). For the most part, every discussion of sense of presence in MOOs has privileged one conception of presence: telepresence. In fact, in the 
one empirical study of presence in text-based networked virtual environments, the researchers admit that their instruments "were assessing the feelings of 'being with' instead of "being there" (Towell \& Towell, 1997, online). The bias that seems to limit discussions of presence to telepresence is symptomatic of the text-based limitations of MOOs. Yet, such boundaries can be crossed through a shift in the interface design, integrating the principles that have made Web browsers so effective and prevalent.

Telepresence-being with others through an interface-is fairly obvious in MOOs, which operate primarily as communicative environments. Talking, as in the use of the telephone, gives users a simple means of connecting, as the words of the other person's voice provide social immediacy and intimacy. In addition, MOO communication provides means of communication that are much richer and complex, such as emotes, which allow users to represent nonverbal communication, or actions, to other users.

On the other hand, a sense of virtual presence, or being there in text-only MOOs is possible, but difficult to achieve without a great deal of experience. If physical cueing is lacking, it is hard for new users to interact effectively with others. It takes a great deal of learning and knowledge to imagine the text-only virtual world as a physical space with real human events occurring in it. MOOs do attempt to create the illusion that one acts in a physical place, that the user is situated. However, this situating occurs through textual descriptions of the space, textual lists of exits, and textual expressions of actions that occur. Presence should suggest more to our human physical reality. Clicking on an object connects the physical act to the virtual as direct manipulation. If one wishes to take something in the real world, she reaches out and takes it. If she wishes to go somewhere, she gets up and goes. If she wishes to look at something, she moves her eyes and her head to look at it. In graphically based MOOs such as we have developed at SLCC and DSU, each of these actions is connected with the physical act of moving the cursor and clicking. Admittedly, it isn't much of a physical movement, but it seems more intuitive than typing a command like look cup. The physical action of actually moving the mouse and clicking on an object is more intuitive than simply typing in commands. In other words, if the user were virtually picking up an object, the act of moving the mouse and clicking on the item is more equivalent to physically picking up an object.

\section{Designing Graphical Interfaces}

Our response to the problems presented by completely textual interfaces was to program graphical user interfaces for our MOOs, taking into account the context, needs, and goals of the user. Our initial efforts centered around the creation of rudimentary Web pages the MOO server could serve to traditional Web-browsing software, but our focus soon shifted to a freeware program-Pueblo (see http://www.chaco.com/). Pueblo allowed us to present our MOOs in an easy-to-use graphical manner that allows users to point and click their way around (see Figure 2). Although we have not abandoned the use of Web pages and our research into other visually based interfaces to make VWCMOO and VTCMOO more accessible, PUEBLo has been the main focus of our programming efforts. It allows programmers to design the interface with the previous outlined principles in mind.

According to its manufacturers, PUEBLO allows MOO developers "to create immerse virtual worlds, with sound, hypertext, 2D and 3D graphics" (Chaco Inc., 1996, online). While providing the same features of the MOO as traditional nongraphical TELNET clients, 
WTCNOO - PUEKLO

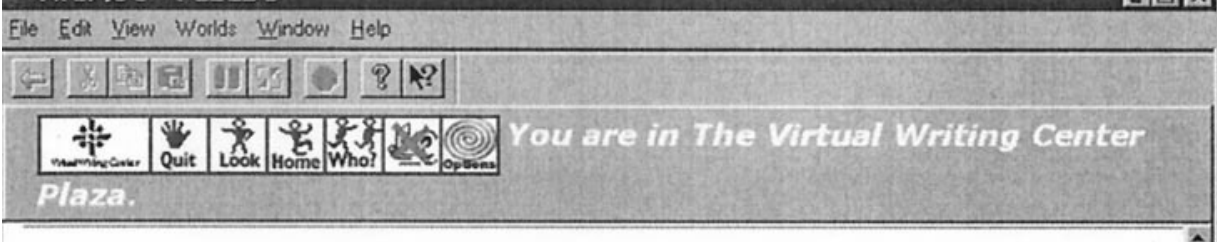

The Virtual Writing Center Plaza

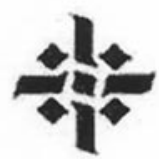

Virtual Writing Center

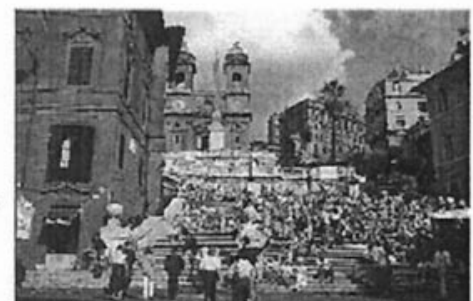

The Plaza is an open courtyard at the center of the Virtual Writing Center. You look around and notice how pleasant and sunny the place seems to be. The red terra-cotta brick paving is warm. Sunlight glints off a puddle of water at your feet. IF YOU ARE NEW TO MOOING, TYPE 'HELP' A map is permanently attached to the wall. A woman sits on the bench reading her book. You see ground, stone bench, and bench to sit upon. You see a plaque, plazacam, MOO Policies, map of vwc, plaza video display, and Maxine Moo here. You teleport. Clint arrives.

XExits: [Writing Advising | Library | The Writer's Cafe I Auditorium | Classroom Hall | Bookstore I VWC Web Chat I Train Station I ]

Orline 3 min

$3.03 \mathrm{PM}$

Figure 2. PUEBLO graphical interface accessing VWCMOO. ${ }^{2}$

PUEBLO can display graphics, support HTML codes, play sound and other multimedia files, offer hypertext links to outside documents, and provide clickable links to commands and rooms on the MOO. In all, PUEBLO has many of the same attributes of a Web browser. PUEBLO's clickable links look similar and perform similar functions as a Web browser's links while providing for synchronous communication. Most users learn to use Web browsers rather quickly, because they offer intuitive cues as to how to read other documents.

PUEBLO assists the MOO user by offering them:

1. a clickable navigation bar to move from room to room;

2. a command bar for common MOO commands such as @ who to see where people are or look to see what is in a room;

\footnotetext{
${ }^{2}$ The screen is subdivided into three sections: a reading pane, a movement (exits) pane, a command bar, and a typing pane. Note the use of graphics in the reading window to help MOO users place themselves inside the virtual world. The "Exits" list allows users to click on the places listed to go to them. Like the Web, items can be made into hyperlinks to materials on the Internet or within the MOO.
} 


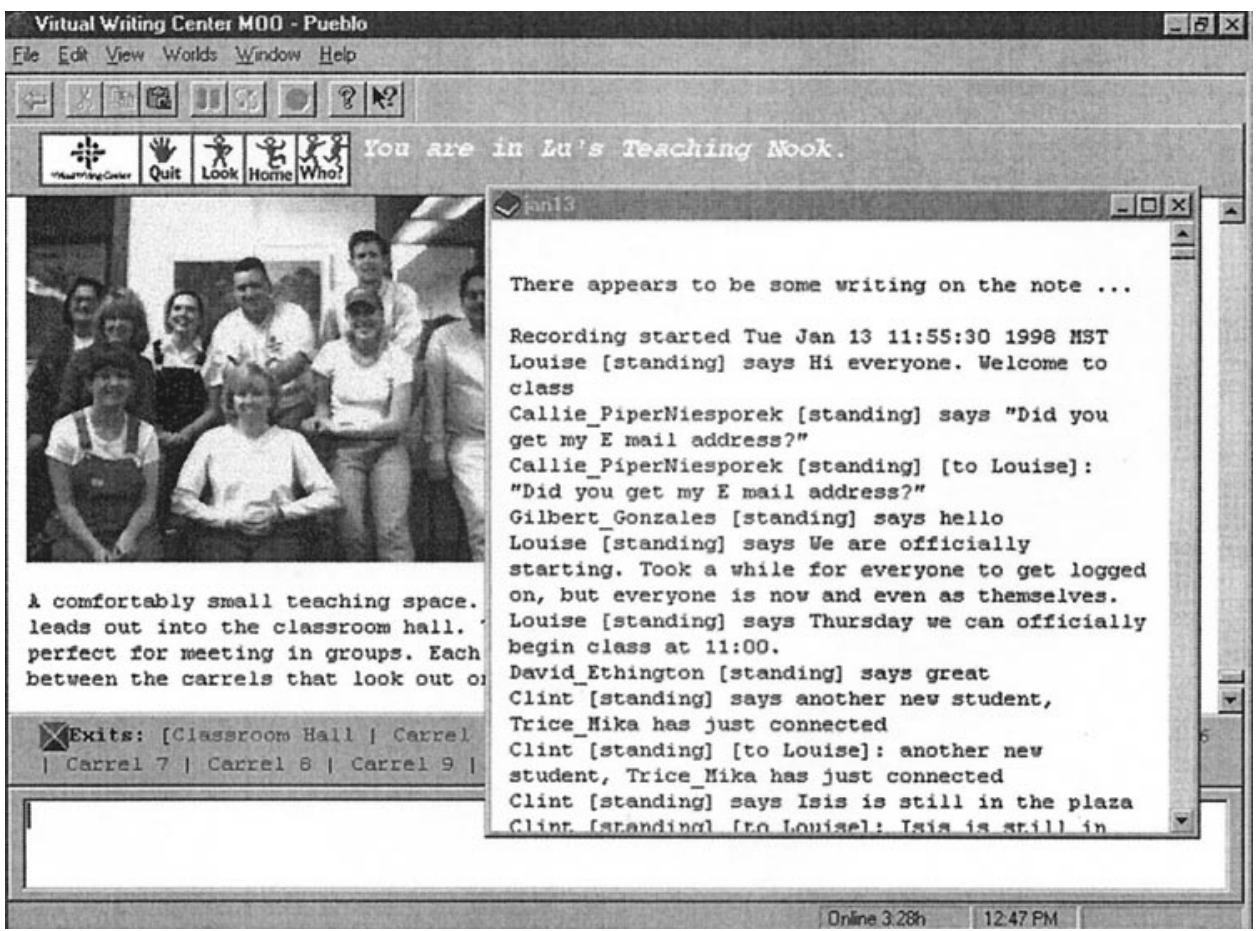

Figure 3. PUEBLO with a pop-up window showing the past conversation in the room. ${ }^{3}$

3. graphical representations of the room users are in, including pictures and clickable links to objects in the room such as notebook, blackboards, mail accounts, logs of discussions, etc., in clearly differentiated pop-up windows (see Figure 3);

4. links displayed within the MOO to Web documents stored outside the MOO. (A user's Web browser works in conjunction with PUEBLO to display such documents);

5. the ability to share information from other spaces and programs more easily via Web links, or through cutting and pasting from one program into PuEBLO; and,

6. other multimedia, such as sounds, music files, and some plug-in technologies can be displayed directly through the PuEBLO interface.

\section{Limitations of Pueblo}

Although we found that PueBLo is a highly effective and useful client in helping people to make better use of the MOO, the program does have serious limitations: It can only be used on Microsoft Windows systems, and the program has been placed on hiatus by its new owners. The operating system limitation is PUEBLO's biggest drawback. Although it did not matter so much at SLCC and DSU where virtually all the computers students used are Windows-based, we did find that users outside the institutions using non-WINDOws

\footnotetext{
${ }^{3}$ The window allows the user to read the previous conversation, thus lessening the impact of a quick-paced conversation.
} 
systems were stuck with traditional text-only clients. In essence, this operating-system block left them with no interface solution. Likewise, the single operating system design limits PUEBLO's expansion to institutions that don't use computers with Microsoft WINDOWs systems.

However, the limitation on development of Pueblo is less drastic than it may first seem. Although the original owners, Chaco Communications, have merged with another business and have ceased actively developing PUEBLO, the program is still readily available on the Internet, the PUEBLo source code is currently up for sale, and Glenn Crocker (a member of the original Pueblo design team) is working on a "next generation mud client that takes some ideas from clients like PUEBLO and casts them in a more modern light" (Crocker, 1998, online). This client, apparently, is a similar program that operates out of the user's Web browser using Java. We must emphasize, however, that PUEBLO itself is by no means a dead project or program. We are certain, in fact, that as the program is increasingly implemented, the desire for further development will increase as well.

To address the current limitations of Pueblo, we began to explore nonsystem dependent clients that were based on the same graphical-interface principles we have applied in PuEBLO, including developing an interface that relies on the user's Web browser. Because most operating systems have Web browsers created for them, we reasoned that users with different operating systems could take advantage of a graphical interface as a PUEBLO user could.

\section{Designing the WOO interface-integrating the MOO with the Web}

Working with Charles Willgren (a very knowledgeable high school student from Austin, Texas), we utilized the latest MOO technology for integrating a MOO and the Web, something called a WOO. A WOO is an object on a MOO, written in MOO code that produces on-the-fly Web pages that are sent back to a Web browser. The WOO works by gathering the necessary information from the object, generating a consistent Web-page format, and then sending the HTML for the page to the browser requesting it. Thus, every object on the MOO can be viewed on the Web, giving people access to the information in either application. (An example is the Trojan Center Lobby, available at http:// alpha.dsu.edu:6666/bob/11). With the WOO, then, we found a potential answer for how to provide a variety of delivery and pedagogy options within an accessible framework of technology.

The Virtual Trojan Center MOO (VTCMOO) is based on the student union at Dakota State University. After considering the goal of presence discussed above, we at DSU decided to recreate the physical space of the actual Trojan Center (TC) within the virtual MOO environment. The rooms were created in fairly proper order. A building directory (http://alpha.dsu.edu:6666/bob/148) that contains a listing of the main rooms in the TC is also a client-side imagemap on the WOO, so users can click on the room they wish to go to rather than walking through the room/pages.

Having the basic layout of the VTCMOO complete, the next consideration was the look of the Web pages generated by the WOO. In keeping with the desire to create a sense of presence, the criteria considered included: consistency of format, visual presentation of information, and ease of navigation. The WOO constructs a page that contains all the 


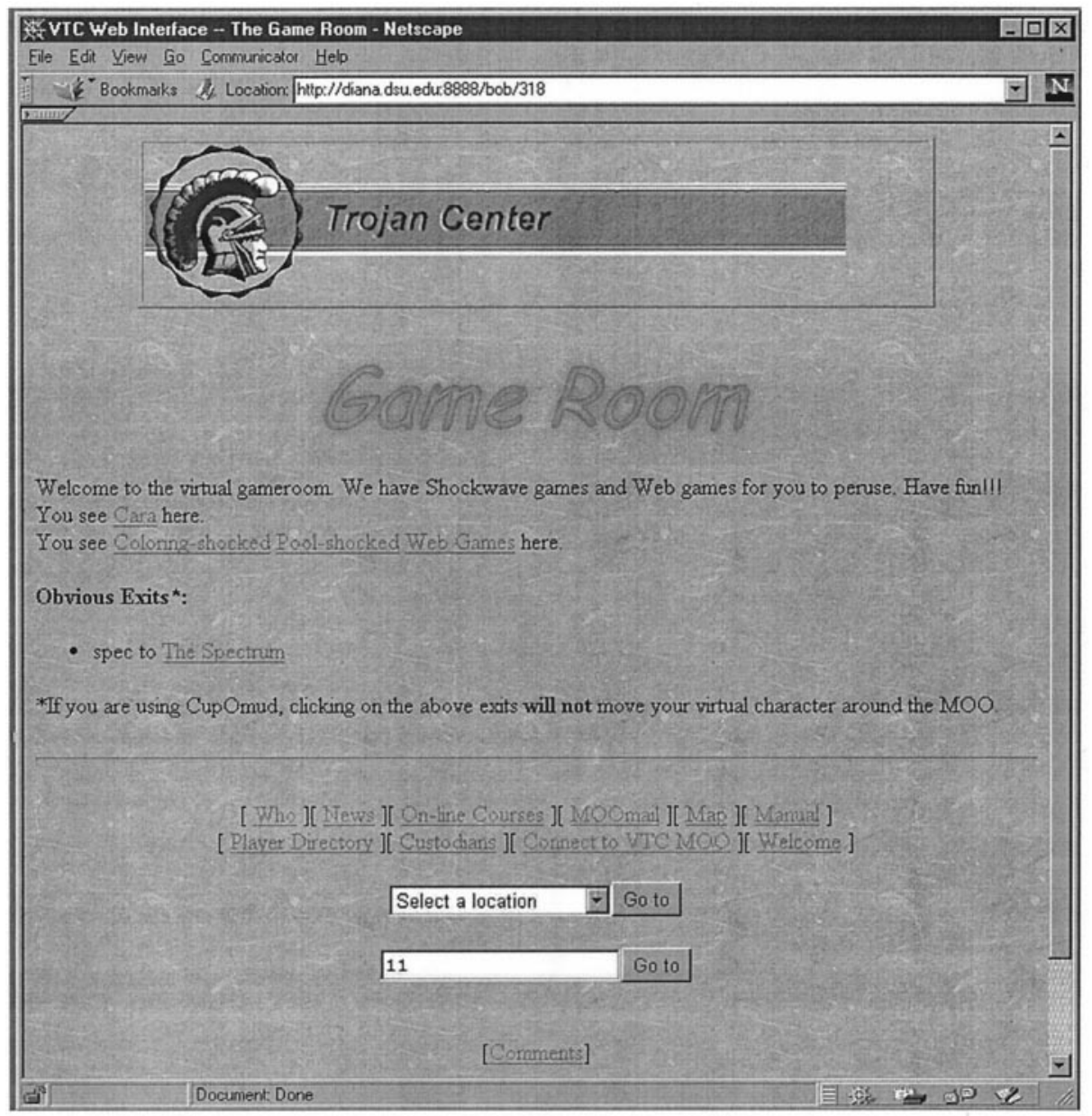

Figure 4. Netscape NAVIGATOR with a WOO page for the Virtual Trojan Game Room. ${ }^{4}$

information in a rhetorically relevant and consistent manner. An example of this setup is the game room (see http://alpha.dsu.edu:6666/bob/318 and Figure 4).

As with the PUEBLO interface, to create a consistent format of information, we provided the user with a quick way to gain the information needed without wondering where it might be. The user knows what will be included on each page after a short time of use, and surprises are kept to a minimum. Added buildings and rooms followed the setup of the campus, and were given spatial relationship through an imagemap of the campus (see http://alpha.dsu.edu:6666/bob/280).

The MOO has a mailing system within it, so players can mail each other within the MOO. Initially, the mailing features of the MOO were only usable from the TELNET side, using a line editor with all the complexity of a command-line interface. We programmed

${ }^{4}$ The page includes a header, description of the room, background image, and common footer. 
a Web mail system (see http://alpha.dsu.edu:6666/blargh) that allows people to access, delete, and send their MOOmail from a Web browser. The system is password-protected, so users must have an account on the MOO to access the system (guests can log in with limited success). This allows students and teachers to use a common MOOmail system instead of dealing with the variety of mail programs that students often have.

As a final note on interface development, to allow for real-time communication from the WOO, VTCMOO and VWCMOO are accessible through Java-enabled Web browsers. Using an applet named CuPOMUd (Stewart, 1997), users may log in to the MOO from the Web, and view the corresponding Web page in a frame above the applet (see http:// bessie.englab.slcc.edu/java/cupovwc.html). As a result, users don't need to use a TELNET client to gain the synchronous aspects of the MOO-they can view the graphics in the WOO frame, and interact with other players in the applet frame. Therefore, for those who do not have access PUEBLO, the Java applet provides similar access.

\section{Effects of the Graphical Interfaces on Composition Courses}

Developing these diverse interfaces had positive effects on how students participated in our MOOs. For example, when we first implemented PUEBLo, the learning time of students in our computer-mediated courses shrank drastically. Students did not need to know as many MOO commands as they did with bare TELNET, and did not have to read the MOO as intently to understand what room they were in at any given time. Instructors discovered students were getting online much more quickly, were able to move about the MOO with little confusion, could manipulate objects on the MOO without trouble, and started discussions more readily than they did in the nongraphical interface. Instead of taking two weeks to train students in using the MOO for SLCC's Online English 1010, for example, the training for new MOO users had dropped to less than 20 minutes. Similarly, at DSU, students were introduced to the MOO the first day of class and were able to use it with minimal problems thereafter. In fact, they often asked to use the MOO rather than have oral discussions. Most students have shown they have very little difficulty remembering how to get on the MOO, move around, and begin discussions with their colleagues. Because students learn to use PUEBLO and other graphical interfaces more quickly, they are better able to engage in fruitful conversations with their colleagues almost immediately.

In evaluations of their use of the MOO in classes, students have stated that they believe the graphical MOO interfaces are easier to operate and more appealing to them as a medium for conversation. For example, one student compared the PUEBLo interface to a Web chat program she had also participated in. Although she was not used to the concept of the MOO or any chat system as a virtual world, she claimed she liked the graphical MOO better because she could move to other rooms and have one-on-one conversations with her classmates and she felt she was more involved in the conversation because it felt like she was "there."

Several students were familiar with Internet Relay Chat (IRC) channels, another form of text-only chat that gives its users little sense of presence. They found the MOO to be more interesting and easier to use as well. Instructors at DSU and SLCC have found that students begin conversations more quickly than previously, and have a better sense of place and community.

We believe that graphical MOOs provide a better means of communication for students 
because they incorporate not only a familiar, easy-to-use interface, but also provide a better sense of presence with other users. The sense of presence goes beyond telepresence, or being with to virtual presence or being there, unlike, for instance, Web chats, which generally provide no sense of presence at all. Although MOO enthusiasts have long made claims for better presence on MOOs, we have concluded that a graphical interface brings more interface comfort to the user and thus they more easily interact with fellow students.

\section{CONCLUSION}

Like the Web, the graphical interface is also more enticing and easy to use. Although conversations on the MOO still contain multiple threads and can become quite complex, the MOO interface no longer exacerbates that complexity. Furthermore, because of its similarity to the Web, we have seen more people interested in learning more about MOOs and MOOing than previously. Instead of being called oldfashioned or out-of-date, a graphically enhanced MOO appeals to more current sensibilities and desires of users. The graphical interface permits the user to explore leading-edge technologies. In this exploration, the user shares in the development and expansion of the MOO project. A fortunate side effect of research in graphical MOO interfaces is that they help to insure that MOOs do not disappear as CMC environments. The appeal of the new interfaces has encouraged many new MOO users to become involved in design and programming, and has revived interest in MOOs for users who stopped using MOOs after other Web-based CMC environments were developed. Because of their newfound relevancy to current notions of human-computer interaction, MOOs with graphical interfaces push the perceived limits of the text-only origins of MOOs. Continued research, design, and experimentation with other different types of interfaces for MOOs is essential to assure that MOOs remain accessible to users, and that MOOs do not become outdated and unused communication environments.

Mark Haas is an assistant professor of English and Director of the Center for Documentation Research at Dakota State University. He received his DA in English in 1996 from Illinois State University. His areas of interest include rhetoric and composition, genre studies, technical communication, and alternative delivery in distance education.

Clinton Gardner teaches composition and directs the Writing Center at Salt Lake Community College (SLCC) in Salt Lake City, Utah. Long interested in CMC and its effects on composition, Gardner has developed SLCC's Online Writing Center with his colleagues as a means of fostering the study of composition at SLCC.

\section{References}

Bardini, Thierry. (1997). Bridging the gulfs: From hypertext to cyberspace. Available: http:// www.ascusc.org/jcmc/vol3/issue2/bardini.html [Accessed March 11, 1998].

Barker, Thomas, \& Kemp, Fred. (1990). Network theory: A postmodern pedagogy for the writing classroom. In Carolyn Handa (Ed.), Computers and community: Teaching composition in the twenty-first century (pp. 1-27). Portsmouth, NJ: Boynton/Cook Publishers. 
Bown, Louise. (1996). Online English 101 at Salt Lake Community College. Available: http:// www.slcc.edu/wc/papers/CWC.HTM [Accessed March 11, 1998].

Bown, Louise, \& Ruffus, Stephen. (1998). HETI final report: Online English 101. Available: http://www.slcc.edu/wc/bowruf/hetislcc.htm [Accessed March 11, 1998].

Bruckman, Amy. (1992) Identity workshops: Emergent social and psychological phenomena in text-based virtual reality. Available: http://lucien.berkeley.edu/MOO/identity-workshop.ps [Accessed March 11, 1998].

Chaco, Inc. (1996). PuEBLo 2.0 feature list. Available: http://www.chaco.com/pueblo/doc/pueblo2.0.html [Accessed March 11, 1998].

Crocker, Glenn. (27 July, 1998). Re: Future of Pueblo. [Email].

Curtis, P. (1993). Mudding: Social phenomena in text-based virtual reality. Available: http:// lucien.berkeley.edu/MOO/DIAC92.ps [Accessed March 11, 1998].

Daedalus Group, Inc. (1997). Daedalus INTERCHANGE. Available: http://www.daedalus.com/info/ interchange-info.html [Accessed March 11, 1998].

Ebersole, Samuel. (1997). Cognitive issues in the design and deployment of interactive hypermedia: Implications for authoring WWW sites. Interpersonal Computing and Technology: An Electronic Journal for the $21^{\text {st }}$ Century, 5(1-2), 19-36. Available: http://www.helsinki.fi/ science/optek/1997/n1/ebersole.txt [Accessed March 11, 1998].

Eklund, John. (1995). Cognitive models for structuring hypermedia and implications for learning from the world-wide web. AusWeb95 Conference, Ballina, New South Wales, Australia. Available: http://www.scu.edu.au/sponsored/ausweb/ausweb95/papers/hypertext/eklund/ index.html [Accessed March 11, 1998].

Gardner, Clinton. (1998). Writing advising. The SLCC online writing center. Available: http:// www.slcc.edu/wc/tutoring.htm [Accessed March 11, 1998].

Haas, Mark, \& Peters-Walters, Stacey. (1997). VTCMOO Manual. Available: http://www.diana. dsu.edu/vtc/manual/moobie.htm [Accessed March 11, 1998].

Handa, Carolyn. (1990). Politics, ideology, and the strange, slow death of the isolated computer or why we need community in the writing classroom. In Carolyn Handa (Ed.), Computers and community: Teaching composition in the twenty-first century (pp. 160-184). Portsmouth, NJ: Boynton/Cook Publishers.

Hawisher, Gail, \& Selfe, Cynthia. (Eds.). (1991). Evolving perspectives on computers and composition studies: Questions for the 1990s. Urbana, IL: National Council of Teachers of English.

Langston, M. Diane, \& Batson, Trent W. (1990). The social shifts invited by working collaboratively on computer networks: The ENFI project. In Carolyn Handa (Ed.), Computers and community: Teaching composition in the twenty-first century (pp. 140-159). Portsmouth, NJ: Boynton/Cook Publishers.

Lombard, Matthew, \& Ditton, Theresa. (1997). At the heart of it all: The concept of presence. Available: http://www.ascusc.org/jcmc/vol3/ussue2/lombard.html [Accessed March 11, 1998].

Schneiderman, B. (1982). The future of interactive systems and the emergence of direct manipulation. Behavior and Information Technology, 1(3), 237-256.

Selfe, Cynthia. (1990). Technology in the English classroom: Computers through the lens of feminist theory. In Carolyn Handa (Ed.), Computers and community: Teaching composition in the twenty-first century (pp. 118-139). Portsmouth, NJ: Boynton/Cook Publishers.

Selfe, Cynthia, \& Hilligoss, Susan. (Eds.). (1994). Literacy and computers: The complications of teaching and learning with technology. New York: Modern Language Association.

Skubikowski, Kathleen, \& Elder, John. (1990). Computers and the social contexts of writing. In Carolyn Handa (Ed.), Computers and community: Teaching composition in the twenty-first century (pp. 89-105). Portsmouth, NJ: Boynton/Cook Publishers. 
Stewart, Alex. (1997). Cup-O MUD: The adventure continues. . . Available: http://www.du.org/ java/CupOmud [Accessed March 11, 1998].

Stone, Elisa. (1996). Computerized writing classrooms as sites for social change: Negotiating gender and technology. Paper presented at the Computers and Writing Conference, Logan, UT.

Towell, John Foster; Hansen, Paul; Mercer, Eric; Leach, Martin; Rubin, Irit; Prilusky, Jaime; \& Glusman, Gustavo (1995, November). Networked virtual environments and electronic conferencing. In Stephen M. Bachrach, Donald. B. Boyd, S. K. Gray, W. Hase, \& Henry Rzepa (Eds.), Proceedings of the First Electronic Computational Chemistry Conference [CDROM]. ARInternet: Landower, MD.

Towell, John F., \& Towell, Elizabeth R. (1995). Internet conferencing with networked virtual environments. Internet Research, 5(3), 15-22.

Towell, John F., \& Towell, Elizabeth R. (1997). Presence in text-based networked virtual environments or "MUDs." Presence, 6(5), 590-595. Available: http://www.mca.anl.gov/home/ towell/presence.html [Accessed March 11, 1998].

Ziegler, J. E.; Vossen, P. H.; \& Hoppe, H. U. (1990). Cognitive complexity of human-computer interfaces: An application and evaluation of cognitive complexity theory for research on direct manipulation-style interaction. In P. Falzon (Ed.), Cognitive ergonomics: Understanding, learning and designing human-computer Interaction (pp. 27-38). San Diego, CA: Academic Press. 